\section{Chlorine isotope evidence for multiple Farallon-derived components in the North American lithospheric mantle}

\author{
GEORGE SEGEE-WRIGHT, JAIME D. BARNES AND \\ JOHN C. LASSITER
}

University of Texas at Austin

Presenting Author: ghs562@utexas.edu

Flat slab subduction of the Farallon plate beneath North America metasomatized the sub-continental lithospheric mantle (SCLM) beneath the Colorado Plateau and Rio Grande Rift. Marshall et al. [2017] suggested a subducted serpentinite or gabbroic altered oceanic crust (AOC) source of metasomatizing fluids [1]. We examine the chlorine isotope ratios $\left(\delta^{37} \mathrm{Cl}\right)$ of hydrous-mineral-bearing peridotite xenoliths from the Navajo Volcanic Field (NVF; Colorado Plateau) and anhydrous mantle xenoliths from Elephant Butte (EB; central Rio Grande Rift) to further constrain the source of Farallon-derived fluids.

NVF xenoliths have high $\mathrm{Cl}$ abundances (30-330 ppm) and high $\delta^{37} \mathrm{Cl}$ values $(+0.3 \%$ to $+1.9 \%$ o) relative to the depleted mantle $\left([\mathrm{Cl}]=1-10 \mathrm{ppm}, \delta^{37} \mathrm{Cl}=-0.2 \%\right.$ o $)$ [2]. Similarly, one EB xenolith has a $\delta^{37} \mathrm{Cl}$ value of $+1.2 \%$ and a $\mathrm{Cl}$ abundance of 17 ppm. The similarity between $\mathrm{EB}$ and $\mathrm{NVF} \delta^{37} \mathrm{Cl}$ values indicates that the EB SCLM has been cryptically metasomatized by the same fluid as the NVF SCLM.

Xenolith $\delta^{37} \mathrm{Cl}$ values negatively correlate with clinopyroxene $\delta^{18} \mathrm{O}$ and positively correlate with bulk xenolith $\mathrm{Br} / \mathrm{F}$ and $\mathrm{I} / \mathrm{F}$ ratios. The $\delta^{37} \mathrm{Cl}$ values also correlate with relative abundance of hydrous minerals (e.g. chlorite abundance relative to overall hydrous mineral abundance), indicating either $\mathrm{Cl}$ isotope fractionation, a single heterogeneous metasomatic fluid source, or multiple fluid sources. Given that chlorine isotopes do not fractionate significantly at mantle temperatures [3], the latter two possibilities are more likely. The higher $\delta^{37} \mathrm{Cl}$ values are consistent with a subducted gabbroic AOC source [4]. The lower $\delta^{37} \mathrm{Cl}$ values are consistent with a subducted serpentinite [5], AOC [4], or sediment source [6] (Figure 1). The high $\mathrm{Cl}$ abundance in all analyzed xenoliths disfavors a significant sediment source. This work demonstrates that subducted AOC and potentially serpentinite significantly enrich the SCLM with $\mathrm{Cl}$, isolating $\mathrm{Cl}$ from cycling between the surface and the convecting mantle for up to $1 \mathrm{Ga}$.

[1] Marshall et al. (2017), Geology 45, 1103-1106.

[2] Sharp et al. (2007), Nature 446, 1062-1065.

[3] Schauble et al. (2003), GCA 67, 3267-3281.

[4] Barnes \& Cisneros (2012), Chem. Geol. 326, 51-60.

[5] Barnes \& Sharp (2006), Chem. Geol. 228, 246-265.

[6] Barnes et al. (2008), Geology 36, 883-886.

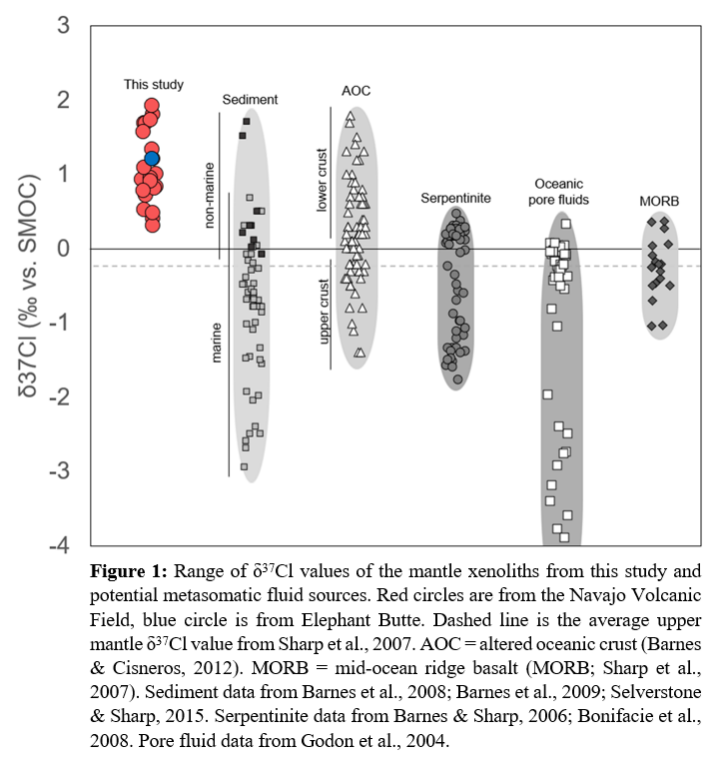

